\title{
Synchronicity: policing multiple aspects of gene expression by Ctk1
}

\author{
Michael Hampsey ${ }^{1}$ and Terri Goss Kinzy ${ }^{2,3}$ \\ ${ }^{1}$ Department of Biochemistry, Division of Nucleic Acid Enzymology, University of Medicine and Dentistry \\ of New Jersey-Robert Wood Johnson Medical School, Piscataway, New Jersey 08854, USA; ${ }^{2}$ Department of Molecular \\ Genetics, Microbiology and Immunology, University of Medicine and Dentistry of New Jersey-Robert Wood Johnson \\ Medical School, Piscataway, New Jersey 08854, USA
}

Transcription and translation are coordinated events in all organisms. In prokaryotes, the process that couples these two events is clear: The ribosome begins translation of the nascent mRNA while the DNA template is still being transcribed. Indeed, cotranscriptional protein synthesis underlies key regulatory mechanisms in bacteria, including attenuation, the mechanism that regulates RNA polymerase processivity in response to ribosome movement along the mRNA. But how is transcription coordinated with translation in eukaryotic organisms, where mRNA is synthesized in the nucleus and protein synthesis occurs in the cytoplasm? Although these two events are spatially distinct, separated by the nuclear envelope, efficient control of gene expression necessarily requires that transcription and translation be regulated in a coordinated manner. As an example, dFOXO-mediated transcriptional activation produces both an inhibitor of cap-dependent translation, eukaryotic translation initiation factor 4E (eIF4E)-BP, and a form of the insulin receptor mRNA that is translated by a cap-independent mechanism (Marr et al. 2007). In addition, translation requires a fully and accurately processed mRNA, and has mechanisms to help sense that appropriate processing has occurred.

In the absence of physical coupling of transcription and translation, how are these two processes coordinated in eukaryotes? In this issue of Genes \& Development, Röther and Sträßer (2007) report that the Ctk1 kinase, a key enzyme that facilitates passage of RNA polymerase II (Pol II) through specific stages of the transcription cycle, is also found in the cytoplasm associated with ribosomes actively engaged in protein synthesis (Fig. 1). Their work defines a physiological role for Ctk 1 in translation by showing that cellular depletion of Ctk1 decreases total protein synthesis as well as the fidelity of translation elongation. These effects are likely to be a direct effect of Ctk1, since they identified the small ribosomal subunit protein $\mathrm{rpS} 2$ as the specific target of the kinase. Moreover, site-directed replacement of $\mathrm{rpS} 2$

${ }^{3}$ Corresponding author.

E-MAIL kinzytg@umdnj.edu; FAX (732) 235-5223.

Article is online at http://www.genesdev.org/cgi/doi/10.1101/gad.1564807.
Ser238, which they identified as the target of Ctk1, results in the same translational defects as depletion of Ctk1. Thus, Röther and Sträßer (2007) propose that Ctk1 piggybacks with either the mRNP particle or with the pre-40S ribosomal subunit to transit the nuclear envelope to regulate protein synthesis in the cytoplasm.

Ctk1 was first identified as a subunit of the yeast CTDK-I complex that catalyzes phosphorylation of the Pol II C-terminal domain (CTD) (Sterner et al. 1995), a reiterated heptapeptide sequence (Tyr1-Ser2-Pro3Thr4-Ser5-Pro6-Ser7) present at the C terminus of Rpb1 (Kobor and Greenblatt 2002). The CTD couples Pol II transcription with RNA processing, apparently forming a platform for the association and exchange of transcription and RNA processing factors (Hirose and Manley 2000; Orphanides and Reinberg 2002; Proudfoot et al. 2002; Bentley 2005; Meinhart et al. 2005). These factors include the $5^{\prime}$-capping enzymes, the splicing machinery, the $3^{\prime}$-end processing complex, and the transcription export complex (TREX) that facilitates mRNA translocation to the cytoplasm. Progression of Pol II through the transcription cycle is accompanied by changes in the phosphorylation status of the CTD. Pol II is recruited to the promoter in an unphosphorylated form (Pol IIA) that becomes extensively phosphorylated at Ser2 and Ser5 during different stages of the transcription cycle. Differential CTD phosphorylation promotes the exchange of initiation and elongation factors at promoter clearance (Pokholok et al. 2002) and the exchange of elongation and $3^{\prime}$-end processing factors at termination (Kim et al. 2004).

CTD phosphorylation is catalyzed by C-type cyclindependent kinases (Prelich 2002). The first of these complexes to be identified is Kin28-Ccl1, which functions as a subcomplex of the general transcription factor TFIIH. Kin28 catalyzes Ser5 phosphorylation coincident with transcription initiation and as a prerequisite for capping (Hengartner et al. 1998; Rodriguez et al. 2000). The second complex, CTDK-I, is composed of three subunits, the Ctk1 kinase, Ctk2 cyclin, and Ctk3 accessory protein that forms a regulatory complex with Ctk2 (Sterner et al. 1995; Hautbergue and Goguel 2001). CTDK-I catalyzes Ser2 phosphorylation during elongation, coinci- 


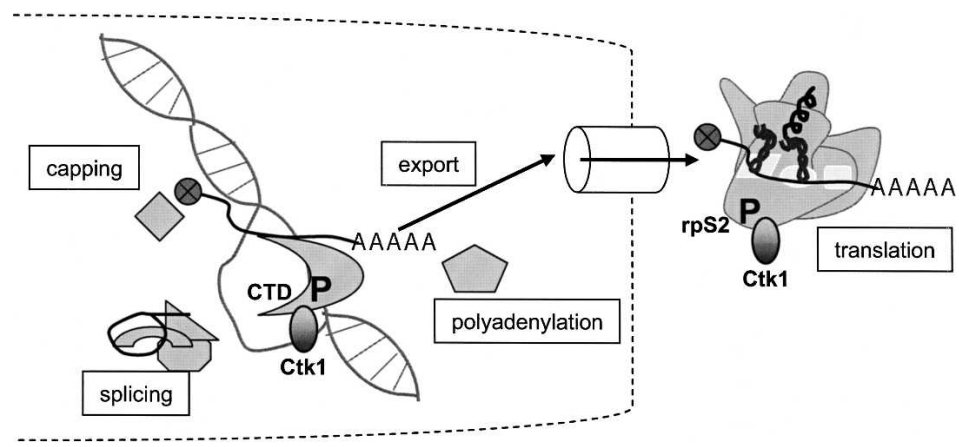

Figure 1. Coordination of eukaryotic Pol II transcription, mRNA processing, and protein synthesis. RNA processing, which includes $5^{\prime}$-cap addition, splicing, $3^{\prime}$ polyadenylation, and nuclear export, occurs cotranscriptionally in a manner coordinated by the Pol II CTD. Progression of Pol II through the transcription cycle is regulated by CTD phosphorylation, catalyzed by the Kin 28 and Ctk 1 cyclin-dependent protein kinases. The processed mRNA is transported to the cytoplasm, where it becomes a substrate for the translational apparatus. The Ctk1 kinase (shaded oval) phosphorylates $(\mathrm{P})$ both the CTD of Pol II on Ser2 in the nucleus and Ser238 of the small ribosomal subunit protein rpS2 in the cytoplasm. dent with diminished Ser5 phosphorylation (Cho et al. 2001). The Kin28-Ccl1 and Ctk1-Ctk2 kinase-cyclin pairs are phylogenetically conserved and correspond, respectively, to the mammalian Cdk7-cyclin $\mathrm{H}$ and Cdk9cyclin K (P-TEFb) complexes (Peterlin and Price 2006). Two other CTD kinase-cyclin pairs, Srb10-Srb11 and Bur1-Bur2, have also been identified in yeast. Srb10Srb11 plays a repressive role in transcription by converting the initiation-competent IIA form of Pol II to the IIO form, thereby precluding Pol II assembly into the transcription preinitiation complex. The physiological role of Bur1-Bur2 in CTD phosphorylation is unclear, as Bur1 was reported to phosphorylate Rad6, which catalyzes histone $\mathrm{H} 2 \mathrm{~B}$ ubiquitylation during transcription elongation (Wood et al. 2005).

The cotranscriptional modifications of mRNA that occur in the nucleus have dramatic effects on translation in the cytoplasm. Exported mRNAs containing inappropriate introns usually have a premature stop codon and are recognized and degraded by the nonsense-mediated mRNA decay machinery in a translation-dependent manner (Amrani et al. 2006). The 5'-cap structure $\left(\mathrm{m}^{7} \mathrm{GpppN}\right)$ is the binding site for the eIF4E, which binds and recruits mRNA to a $40 \mathrm{~S}$ ribosomal subunit primed with the appropriate initiation factors and Met-tRNA ${ }_{i}{ }^{\text {Met }}$ (Hinnebusch et al. 2007). The poly(A) tail also contributes to the efficiency of translation, where the poly(A)binding protein $(\mathrm{Pab})$ provides communication between the $5^{\prime}$ and $3^{\prime}$ ends of the mRNA, and to initiation by virtue of its direct interaction with the cap-binding complex proposed as a closed loop (Jacobson and Favreau 1983). Once the mRNA is recruited to the 40S ribosome and positioned at the AUG via the action of a series of translation initiation factors (eIFs), the 60S subunit is joined. The $80 \mathrm{~S}$ ribosome with the AUG start codon and Met-tRNA ${ }_{i}{ }^{\text {Met }}$ in the $\mathrm{P}$ site is then primed for translation elongation. The elongation of the growing polypeptide chain subsequently requires efficient and accurate delivery of aminoacyl-tRNA (aa-tRNA) by the eukaryotic Elongation Factor 1A (eEF1A) and translocation by eEF2 (Merrick and Nyborg 2000). When one of the three stop codons occupies that A site, the action of the release factors (eRFs) terminates protein synthesis.

As with every stage of gene expression, accuracy must be maintained. During translation, this includes recog- nition of the appropriate AUG and the use of the MettRNA $_{i}{ }^{\text {Met }}$ at initiation, cognate aa-tRNA selection and the maintenance of the correct reading frame during elongation, and recognition of one of the three stop codons during termination. Mutational analysis has shown that all the components of the translational apparatus-aa-tRNA, rRNA, ribosomal proteins, and the soluble translation factors-contribute to the maintenance of this accuracy (Valente and Kinzy 2003). Genetic approaches have identified mutations of these components of the translational apparatus that alter fidelity during translation elongation. There are also a few examples of cellular proteins produced by altered fidelity, such the programmed +1 ribosomal frameshift of the ornithine decarboxylase antizyme (Ivanov et al. 2000) and UGA readthrough in the Drosophila kelch mRNA (Xue and Cooley 1993). However, examples of conditions where modifications alter the accuracy of translation are not common.

Post-transcriptional and post-translational modifications of components of the translational apparatus also affect the efficiency and/or accuracy of protein synthesis. The target of rapamycin (TOR) pathway plays a key role in signaling that sufficient nutrients and energy are available for protein synthesis, leading to phosphorylation of rpS6, the eEF2 kinase, eIF4E-BP, and other translation factors (Hay and Sonenberg 2004). Effects on the elongation phase of translation are seen as a result of altered modifications of translation components. Failure to form pseudouridine within the rRNA at the peptidyl transferase center of the ribosome results in reduced translation (King et al. 2003), and loss of other rRNAmodifying proteins affects several forms of translational fidelity (Baxter-Roshek et al. 2007). Loss of the diphthamide modification of a specific histidine residue in eEF2 also affects total translation as well as the fidelity of reading frame maintenance (Ortiz et al. 2006). Translation is also affected by phosphorylation of elongation factors. Phosphorylation of eEF1A results in increased activity (Traugh 2001), while phosphorylation of eEF2 by the eEF2 kinase reduces translation (Herbert and Proud 2007).

Alterations in the efficiency and accuracy of translation elongation that result from phosphorylation of the soluble elongation factors or $\mathrm{rpS6}$, or mutations in trans- 
lation components, differ from Ctk1p phosphorylation of rpS2 demonstrated in the work of Röther and Sträßer (2007) in several ways. First, diminished rpS2 phosphorylation associated with either Ctk1 depletion or the Ser238Ala replacement results in reduced translational fidelity at the A site as well as reduced total translation. The increased missense and nonsense errors are not an effect of reduced elongation, as mutants in translation elongation factors that reduce total translation do not always result in altered fidelity. In addition, a phosphorylation event that results in altered translational fidelity is novel. Second, while coordinate regulation of multiple components of the translational apparatus is seen in the TOR pathway, the Ctk1 kinase is not specific to the translational apparatus but also impacts an earlier stage of gene expression. Thus, instead of coordinating a single step of gene expression, Ctk1 might coordinate distinct events in gene expression. The specific effect of Ser238 phosphorylation of $\mathrm{rpS} 2$ on ribosome function remains unknown. The fact that the sup44-1 allele of RPS2, which encodes a Ser200Tyr replacement near Ser 238 , is a paromomycin-sensitive omnipotent suppressor (All-Robyn et al. 1990) suggests that both types of mutants modulate fidelity in a similar way. Prior studies of the rpS2 equivalent in Escherichia coli, rpS5, identified replacements at Gly103 (Sc Gly177) and Arg111 (Sc Lys185) that also reduce fidelity (Piepersberg et al. 1980). It is possible that the fidelity is manifest through the A-site-binding elongation factors, especially eEF1A, which is known to affect missense, frameshift, and nonsense suppression (Sandbaken and Culbertson 1988; Dinman and Kinzy 1997; Cavallius and Merrick 1998). While the location of $\mathrm{rpS} 2$ is not within the A site, its location could modulate the accuracy of aa-tRNA selection, consistent with the effect of Ctk1 depletion or mutation of Ser238.

The effects of Ctk1 on capping, splicing, 3 '-end processing, and mRNA export can all be explained by the coupling of Pol II transcription with RNA processing, a connection that is mediated by differential phosphorylation of the CTD. But the discovery that Ctk1 catalyzes phosphorylation of a substrate other than Ser2 of the CTD is not the first hint of a broader role played by Ctk1 in gene expression. In an effort to identify additional Ctk1 substrates, Goguel and colleagues (Bouchoux et al. 2004) found that Ctk1 is partially localized to the nucleolus and affects Pol I transcription at the rDNA locus. These results were recently extended by showing that Ctk1 affects the stability of the rDNA tandem repeats (Grenetier et al. 2006). It seems unlikely that the effect of Ctk1p depletion on fidelity is related to changes in ribosome synthesis, based both on the results of Röther and Sträßer (2007) and a large bank of ribosome assembly mutants that have been identified but not linked to reduced translational fidelity. Thus, Ctk1 might serve to link or coordinate the path of mRNA from its site of synthesis to its use as a substrate.

How does Ctk1 traverse the nuclear membrane to regulate both transcription and translation? One of the most well-characterized transcription factors in yeast,
Pho4, is regulated by nuclear-cytoplasmic translocation by the Msn5 exportin and Psel importin (Komeili and O'Shea 2000). Are there comparable proteins that regulate subcellular Ctk1 localization and under what physiological conditions? The CTD kinase activity of Ctk1 is regulated by the Ctk2-Ctk3 heterodimer (Hautbergue and Goguel 2001). Do Ctk2 and Ctk3 affect translation? Progression of Pol II through the transcription cycle and the exchange of RNA processing factors also involves CTD dephosphorylation, catalyzed by the Fcp1 and Ssu72 phosphatases (Cho et al. 2001; Mandal et al. 2002; Reyes-Reyes and Hampsey 2007). Is there a cytoplasmic phosphatase that catalyzes rpS2 dephosphorylation? Finally, in light of the association of mammalian Ctk9 kinase with polyribosomes (Röther and Sträßer 2007), it will be especially interesting to learn whether Ctk9 in the P-TEFb complex also affects protein synthesis.

\section{Acknowledgments}

We thank Paul R. Copeland for helpful comments. M.H. is supported by NIH grants GM39484 and GM068887 and T.G.K. is supported by NIH grant GM57483 and NSF grant 0516688.

\section{References}

All-Robyn, J.A., Brown, N., Otaka, E., and Liebman, S.W. 1990. Sequence and functional similarity between a yeast ribosomal protein and the E. coli S5 ram protein. Mol. Cell. Biol. 10: 6544-6553.

Amrani, N., Sachs, M.S., and Jacobson, A. 2006. Early nonsense: mRNA decay solves a translational problem. Nat. Rev. 7: 415-425.

Baxter-Roshek, J.L., Petrov, A.N., and Dinman, J.D. 2007. Optimization of ribosome structure and function by rRNA base modification. PLOS ONE doi: 10.1371/journal.pone.0000174.

Bentley, D.L. 2005. Rules of engagement: Co-transcriptional recruitment of pre-mRNA processing factors. Curr. Opin. Cell Biol. 17: 251-256.

Bouchoux, C., Hautbergue, G., Grenetier, S., Carles, C., Riva, M., and Goguel, V. 2004. CTD kinase I is involved in RNA polymerase I transcription. Nucleic Acids Res. 32: 5851-5860.

Cavallius, J. and Merrick, W.C. 1998. Site-directed mutagenesis of yeast eEF1A: Viable mutants with altered nucleotide specificity. J. Biol. Chem. 273: 28752-28758.

Cho, E.J., Kobor, M.S., Kim, M., Greenblatt, J., and Buratowski, S. 2001. Opposing effects of Ctk1 kinase and Fcp1 phosphatase at Ser 2 of the RNA polymerase II C-terminal domain. Genes \& Dev. 15: 3319-3329.

Dinman, J.D. and Kinzy, T.G. 1997. Translational misreading: Mutations in translation elongation factor $1 \alpha$ differentially affect programmed ribosomal frameshifting and drug sensitivity. RNA 3: 870-881.

Grenetier, S., Bouchoux, C., and Goguel, V. 2006. CTD kinase I is required for the integrity of the rDNA tandem array. Nucleic Acids Res. 34: 4996-5006.

Hautbergue, G. and Goguel, V. 2001. Activation of the cyclindependent kinase CTDK-I requires the heterodimerization of two unstable subunits. J. Biol. Chem. 276: 8005-8013.

Hay, N. and Sonenberg, N. 2004. Upstream and downstream of mTOR. Genes \& Dev. 18: 1926-1945.

Hengartner, C.J., Myer, V.E., Liao, S.M., Wilson, C.J., Koh, S.S., 
and Young, R.A. 1998. Temporal regulation of RNA polymerase II by Srb10 and Kin28 cyclin-dependent kinases. Mol. Cell 2: 43-53.

Herbert, T.P. and Proud, C.G. 2007. Regulation of translation elongation and the cotranslational protein targeting pathway. In Translational control in biology and medicine (eds. N. Sonenberg et al.), pp. 601-624. Cold Spring Harbor Laboratory Press, Cold Spring Harbor, NY.

Hinnebusch, A.G., Dever, T.E., and Asano, K. 2007. Mechanism of translation initiation in the yeast Saccharomyces cerevisiae. In Translational control in biology and medicine (eds. N. Sonenberg et al.), pp. 225-268. Cold Spring Harbor Laboratory Press, Cold Spring Harbor, NY.

Hirose, Y. and Manley, J.L. 2000. RNA polymerase II and the integration of nuclear events. Genes \& Dev. 14: 1415-1429.

Ivanov, I.P., Matsufuji, S., Murakami, Y., Gesteland, R.F., and Atkins, J.F. 2000. Conservation of polyamine regulation by translational frameshifting from yeast to mammals. $E M B O$ J. 19: 1907-1917.

Jacobson, A. and Favreau, M. 1983. Possible involvement of poly(A) in protein synthesis. Nucleic Acids Res. 11: 63536368.

Kim, M., Ahn, S.H., Krogan, N.J., Greenblatt, J.F., and Buratowski, S. 2004. Transitions in RNA polymerase II elongation complexes at the 3 ' ends of genes. EMBO J. 23: 354-364.

King, T.H., Liu, B., McCully, R.R., and Fournier, M.J. 2003. Ribosome structure and activity are altered in cells lacking snoRNPs that form pseudouridines in the peptidyl transferase center. Mol. Cell 11: 425-435.

Kobor, M.S. and Greenblatt, J. 2002. Regulation of transcription elongation by phosphorylation. Biochim. Biophys. Acta 1577: 261-275.

Komeili, A. and O'Shea, E.K. 2000. Nuclear transport and transcription. Curr. Opin. Cell Biol. 12: 355-360.

Mandal, S.S., Cho, H., Kim, S., Cabane, K., and Reinberg, D. 2002. FCP1, a phosphatase specific for the heptapeptide repeat of the largest subunit of RNA polymerase II, stimulates transcription elongation. Mol. Cell. Biol. 22: 7543-7552.

Marr II, M.T., D'Alessio, J.A., Puig, O., and Tjian, R. 2007. IRESmediated functional coupling of transcription and translation amplifies insulin receptor feedback. Genes \& Dev. 21: 175-183.

Meinhart, A., Kamenski, T., Hoeppner, S., Baumli, S., and Cramer, P. 2005. A structural perspective of CTD function. Genes \& Dev. 19: 1401-1415.

Merrick, W.C. and Nyborg, J. 2000. The protein biosynthesis elongation cycle. In Translational control of gene expression (eds. N. Sonenberg et al.), pp. 89-126. Cold Spring Harbor Laboratory, Cold Spring Harbor, NY.

Orphanides, G. and Reinberg, D. 2002. A unified theory of gene expression. Cell 108: 439-451.

Ortiz, P.A., Ulloque, R., Kihara, G.K., Zheng, H., and Kinzy, T.G. 2006. Translation elongation factor 2 anticodon mimicry domain mutants affect fidelity and diphtheria toxin resistance. J. Biol. Chem. 281: 32639-32648.

Peterlin, B.M. and Price, D.H. 2006. Controlling the elongation phase of transcription with P-TEFb. Mol. Cell 23: 297-305.

Piepersberg, W., Geyl, D., Hummel, H., and Bock, A. 1980. Physiology and biochemistry of bacterial ribosomal mutants. In Genetics and evolution of RNA polymerases, $t R N A$ and ribosomes (eds. S. Osawa et al.), pp. 359-377. Tokyo University Press, Tokyo.

Pokholok, D.K., Hannett, N.M., and Young, R.A. 2002. Exchange of RNA polymerase II initiation and elongation factors during gene expression in vivo. Mol. Cell 9: 799-809.

Prelich, G. 2002. RNA polymerase II carboxy-terminal domain kinases: Emerging clues to their function. Eukaryot. Cell 1: 153-162.

Proudfoot, N.J., Furger, A., and Dye, M.J. 2002. Integrating mRNA processing with transcription. Cell 108: 501-512.

Reyes-Reyes, M. and Hampsey, M. 2007. Role for the Ssu72 C-terminal domain phosphatase in RNA polymerase II transcription elongation. Mol. Cell. Biol. 27: 926-936.

Rodriguez, C.R., Cho, E.J., Keogh, M.C., Moore, C.L., Greenleaf, A.L., and Buratowski, S. 2000. Kin28, the TFIIH-associated carboxy-terminal domain kinase, facilitates the recruitment of mRNA processing machinery to RNA polymerase II. Mol. Cell. Biol. 20: 104-112.

Röther, S. and Sträßer, K. 2007. The RNA polymerase II CTD kinase Ctk1 functions in translation elongation. Genes \& Dev. (this issue) doi: $10.1101 / \mathrm{gad} .428407$.

Sandbaken, M.G. and Culbertson, M.R. 1988. Mutations in elongation factor EF-1 $\alpha$ affect the frequency of frameshifting and amino acid misincorporation in Saccharomyces cerevisiae. Genetics 120: 923-934.

Sterner, D.E., Lee, J.M., Hardin, S.E., and Greenleaf, A.L. 1995 The yeast carboxyl-terminal repeat domain kinase CTDK-I is a divergent cyclin-cyclin-dependent kinase complex. Mol. Cell. Biol. 15: 5716-5724.

Traugh, J.A. 2001. Insulin, phorbol ester and serum regulate the elongation phase of protein synthesis. Prog. Mol. Subcell. Biol. 26: 33-48.

Valente, L. and Kinzy, T.G. 2003. Yeast as a sensor of factors affecting the accuracy of protein synthesis. Cell. Mol. Life Sci. 60: 2115-2130.

Wood, A., Schneider, J., Dover, J., Johnston, M., and Shilatifard, A. 2005. The Bur1/Bur2 complex is required for histone H2B monoubiquitination by Rad6/Bre1 and histone methylation by COMPASS. Mol. Cell 20: 589-599.

Xue, F. and Cooley, L. 1993. kelch encodes a component of intercellular bridges in Drosophila egg chambers. Cell 72: 681-693. 


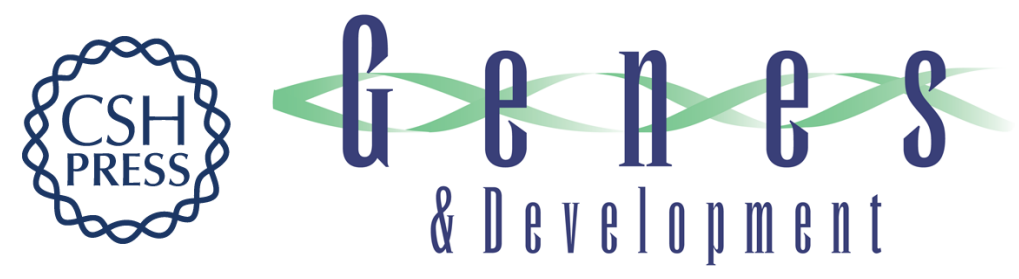

\section{Synchronicity: policing multiple aspects of gene expression by Ctk1}

Michael Hampsey and Terri Goss Kinzy

Genes Dev. 2007, 21:

Access the most recent version at doi:10.1101/gad.1564807

Related Content The RNA polymerase II CTD kinase Ctk1 functions in translation elongation Susanne Röther and Katja Sträßer

Genes Dev. June , 2007 21: 1409-1421

References This article cites 36 articles, 19 of which can be accessed free at:

http://genesdev.cshlp.org/content/21/11/1288.full.html\#ref-list-1

Articles cited in:

http://genesdev.cshlp.org/content/21/11/1288.full.html\#related-urls

\section{License}

Email Alerting

Service

Receive free email alerts when new articles cite this article - sign up in the box at the top right corner of the article or click here.

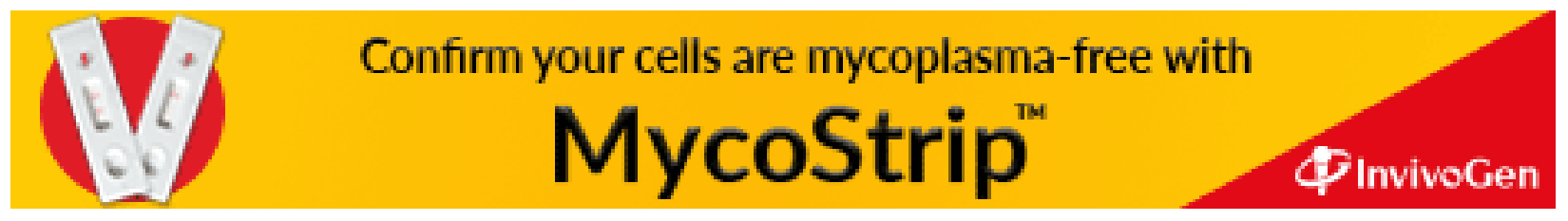

